Ye.I. Baida, M. Clemens, B.V. Klymenko, O.G. Korol, M.G. Pantelyat, P.Ye. Pustovoitov

\title{
PECULIARITIES OF CALCULATING STATIONARY HEATING OF WINDINGS OPERATING IN COMPLEX FORCED CONTROL SYSTEMS
}

\begin{abstract}
Загальний опис теми дослідження. Розглядаються запропоновані авторами методика $і$ алгоритм розрахунку теплового поля електромагнітів, щңо працюють в складних форсованих системах. Широке застосування в електромеханічних комутаційних апаратах подібних пристроӥв дозволяс не тільки підвищити ӥх швидкодію, але також істотно зменшити розміри, масу і втрати енерхї, цио свідчить про актуальність даної теми. Запропонована авторами математична модель нагріву обмоток форсованих електромагнітів являе собою систему одновимірних диференціальних рівнянь стаціонарної теплопровідності в циліндричній системі координат, доповнену рівняннями електричного та магнітного кіл. Ця модель дозволяе врахувати пульсаціі струмів в обмотках, а також втрати в магнітопроводі, обумовлені цими пульсаціями, містить певні ознаки наукової новизни $і$ с метою статті. Розроблений авторами алгоритм розрахунку теплового поля електромагнітів, що працюють в системах форсованого керування, являє собою складний ітераційний цикл, програмування якого істотно спрощується за рахунок застосування математичного пакету Марlе, щьо дозволяє здійснювати складні $i$ громіздкі математичні перетворення, автоматизувати процес розрахункових досліджень, отримувати результати комп'ютерного моделювання в зручній табличній та / або графічній формі, щчо свідчить про практичну значимість даної роботи. Наведені в статті результати зіставлення розрахунків з експериментальними даними, свідать про адекватність запропонованих моделі та алгоритму. Бібл. 17, табл. 1, рис. 7.

Ключові слова: електромагніти, теплове поле, форсоване керування, комутаційні апарати, математичний пакет Марlе, комп'ютерне моделювання.
\end{abstract}

Общее описание темы исследования. Рассматриваются предложенные авторами методика и алгоритм расчета теплового поля электромагнитов, работающих в сложных форсированных системах. Широкое применение в электромеханических коммутационных аппаратах подобных устройств позволяет не только повысить их быстродействие, но такюе суцественно уменьшить размеры, массу и потери энергии, что свидетельствует об актуальности данной темы. Предложенная авторами математическая модель нагрева обмоток форсированных электромагнитов представляет собой систему одномерных дифференцильных уравнений стационарной теплопроводности в цилиндрической системе координат, дополненную уравнениями электрической и магнитной цепей. Эта модель позволяет учесть пульсации токов в обмотках и потери в магнитопроводе, обусловленные этими пульсациями, содержсит определенные признаки научной новизны и является целью статьи. Разработанный авторами алгоритм расчета теплового поля электромагнитов, работающих в системах форсированного управления, представляет собой сложный итерационный цикл, программирование которого суцественно упроцается за счет применения математического пакета Марlе, позволяющего осуществлять сложсные и громоздкие математические преобразования, автоматизировать процесс расчетных исследований, получать результаты компьютерного моделирования в удобной табличной и/или графической форме, что свидетельствует о практической значимости данной работы. Приведенные в статье результаты сопоставления расчетов с экспериментальными данными, свидетельствуют об адекватности предложенных модели и алгоритма. Библ. 17, табл. 1, рис. 7.

Ключевые слова: электромагниты, тепловое поле, форсированное управление, коммутационные аппараты, математический пакет Maple, компьютерное моделирование.

Introduction.

International Standards suggest that electromechanical switching devices can operate in such rated duties: eighthour duty, uninterrupted duty, intermittent duty, temporary duty, and periodic duty. For the coils of such apparatus, the most hard mode in terms of heating their windings (the coil may contain one or more windings) is uninterrupted duty. Therefore, the basic Standard IEC 60947-1:1999, Low-voltage switchgear and controlgear Part 1: General rules indicates that «coils and electromagnets shall be tested ... for a sufficient time for the temperature-rise to reach a steady-state value» (IEC 60947-1, 8.3.3.3.6). At the same time, that Standard makes a reservation that «coils and electromagnets of equipment intended for intermittent duty shall be tested as prescribed in the relevant product standard». Manufacturers rarely use this feature, because if the device is designed to operate in intermittent duty, but operates, for example, in eight-hour duty or in uninterrupted duty, then its coil will necessarily overheat and will be damaged. In this case, it will be difficult for the manufacturer to prove that the damage is due to improper operation, and not to structural defects. Therefore, the vast majority of electromechanical switching devices are oriented to operate in continuous modes (eight-hour or uninterrupted duty), which means to ensure operability in these modes, including in steady state, when the temperature of the windings reaches its maximum value.

The use of forced electromagnetic systems (FEMS) in electromechanical switching devices [1] not only allows to increase their speed, but also to significantly reduce the size, mass and energy losses in an electromagnet.

When designing a switching devices with FEMS, it is necessary to take into account the specific features of heat release in the windings and, possibly, in the magnetic core of the drive electromagnet associated with the pulsations of currents in the windings, as well as the features of heat exchange between the windings and the features of heat transfer from the windings to the magnetic core and to the environment.

Although there are a large number of publications devoted to methods for calculating the heating of electromagnets, some of which are given in References 
[1-9]. In the authors' opinion, insufficient attention has been paid to the processes of heating the windings while taking into account the above features, taking into account the wide variety of existing FEMS and some peculiarities of the operation of forced electromagnets in switching devices. At first glance, the task of calculating the stationary heating of the electromagnet windings may seem quite simple, however, for forced systems, especially in cases where the control device is supplied from an AC voltage source through a rectifier, this task is greatly complicated, taking into account the complex harmonic composition of currents in windings and magnetic core.

The goal of this work is the description of a mathematical model of the process of stationary heating of the windings of electromagnets operating in the FEMS. This model has to take into account the features of heat exchange between the windings, heat transfer from the windings to the magnetic core and the environment, taking into account the ripple currents, and other features of the operation of electro-magnets in FEMC. The algorithm for calculating the temperature distribution in the windings of these electromagnets is focused on using the Maple computing environment, which greatly simplifies the programming process.

The geometric model.

The coils of forced electromagnets, in most cases, are located on cores having a cylindrical shape and are axisymmetrical, even when the electromagnet itself does not have axial symmetry. Thus, the thermal calculation can be performed in a cylindrical coordinate system. A sketch of a coil and a fragment of a magnetic core of a forced electromagnet is shown in Fig. 1. The coil of such an electromagnet can have one or two windings: booster and holding ones, and, most often, the booster winding is wound first, and the holding one is wound on top of it. The axial size $l_{\mathrm{w}}$ of the coil winding space, as a rule, far exceeds its radial size. Therefore, with a high degree of adequacy, the temperature field in it can be considered as $1 \mathrm{D}$ one, which is greatly facilitated by the insulating cheeks of the coil frame.

Heat transfer from the external surface of the second (holding) winding into the environment (air) is carried out through the thickness of the shell from its external surface (Fig. 2), whose area is $S_{\mathrm{e}}$ :

$S_{\mathrm{e}}=2 \cdot \pi \cdot r_{\mathrm{e}} \cdot l_{\mathrm{w}}$,

where $r_{\mathrm{e}}$ is the radius of the external surface of the shell of the coil.

The heat flux $P_{\mathrm{e}}$ dissipated into the surrounding air from the external surface of the coil is equal to:

$P_{\mathrm{e}}=k_{\mathrm{e}} \cdot S_{\mathrm{e}} \cdot \theta_{\mathrm{e}}$

where $k_{\mathrm{e}}$ is the coefficient of heat transfer to the ambient air from the external surface of the shell of the coil; $\theta_{\mathrm{e}}$ is the temperature rise of the external surface of the shell of the coil:

$\theta_{\mathrm{e}}=\vartheta_{\mathrm{e}}-\vartheta_{\mathrm{a}}$,

$\vartheta_{\mathrm{e}}$ is the temperature of the external surface of the shell of the coil, ${ }^{\circ} \mathrm{C} ; \vartheta_{\mathrm{a}}$ is the ambient air temperature.

Expression (2) can be considered as the heat equivalent of Ohm law, in which the role of the electric current is played by the heat flux (power), and the role of voltage is played by the temperature rise. Then the product $k_{\mathrm{e}} \cdot S_{\mathrm{e}}$ is the thermal conductivity $G_{\theta \mathrm{e}}$, i.e., the reciprocal of the thermal resistance $R_{\theta \mathrm{e}}$ :

$R_{\theta \mathrm{e}}=1 / G_{\theta \mathrm{e}}=1 /\left(k_{\mathrm{e}} \cdot S_{\mathrm{e}}\right)$.

Thus, expression (2) can be represented as follows: $P_{\mathrm{e}}=\theta_{\mathrm{e}} / R_{\theta \mathrm{e}}$.

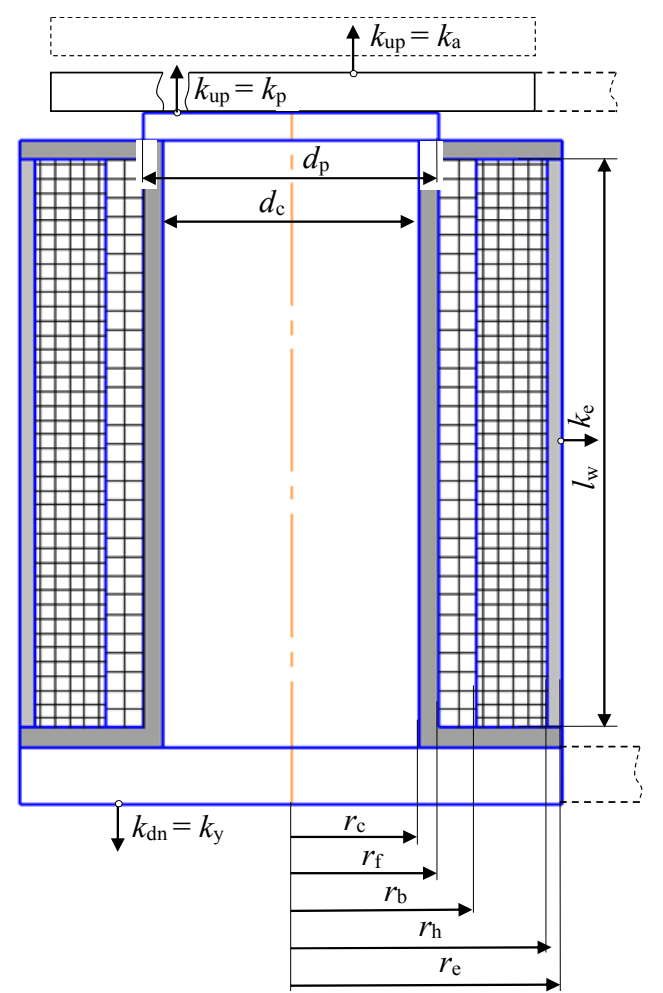

Fig. 1. Sketch of a coil and a fragment of a magnetic core of a forced electromagnet

Heat transfer from the internal surface of the first (booster) winding to the environment is carried out through the thickness of the tubular part of the insulating frame to the core, from it to other parts of the magnetic core, from the external parts of which to the surrounding air.

The heat flux dissipated into the environment from the down part of the magnetic core $P_{\mathrm{dn}}$ is:

$P_{\mathrm{dn}}=k_{\mathrm{dn}} \cdot S_{\mathrm{dn}} \cdot \theta_{\mathrm{c}}=\theta_{\mathrm{c}} / R_{\theta \mathrm{dn}}$.

where $k_{\mathrm{dn}}$ is the coefficient of heat transfer to the surrounding air from the down part of the magnetic core. $S_{\mathrm{dn}}$ is the cooling surface area from the down part of the magnetic core; $\theta_{\mathrm{c}}$ is the temperature rise of the core and adjacent parts of the magnetic core - the yoke, the pole piece and the armature above the temperature $\vartheta_{\mathrm{a}}$ of the ambient air; $R_{\theta \mathrm{dn}}$ is the thermal resistance to cooling from the down part of the magnetic core.

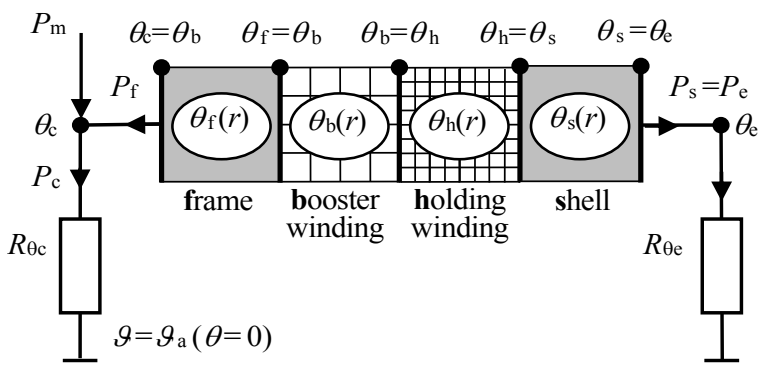

Fig. 2. Equivalent circuit showing the process of heat transfer from the windings of a forced electromagnet to the environment 
In particular, for double-rod electromagnets, as the area of the cooling surface from the bottom part of the magnetic core, with a certain margin in the direction of heating of the windings, we can take:

$S_{\mathrm{dn}}=b_{\mathrm{y}} \cdot l_{\mathrm{yp}} / 2$,

where $b_{\mathrm{y}}, l_{\mathrm{yp}}$ are the breadth and the length of the yoke (piece), respectively.

The heat flux dissipated into the environment from the upper part of the magnetic core $P_{\text {up }}$ is:

$P_{\text {up }}=k_{\text {up }} \cdot S_{\text {up }} \cdot \theta_{\mathrm{c}}=\theta_{\mathrm{c}} / R_{\theta u p}$,

where $k_{\text {up }}$ is the coefficient of heat transfer to the surrounding air from the upper part of the magnetic core; $S_{\text {up }}$ is the cooling surface area from the upper part of the magnetic core; $R_{\theta \text { up }}$ is the thermal resistance to cooling from the upper part of the magnetic core.

If the electromagnet operated and its armature is pulled to the fixed part of the magnetic core, then as $S_{\text {up }}$ for tworod electromagnets, we can take:

$S_{\text {up }}=b_{\mathrm{a}} \cdot l_{\text {ap }} / 2$,

where $b_{\mathrm{a}}, l_{\text {ap }}$ are the breadth and the length of the armature (piece), respectively.

If the electromagnet did not operate and its armature is in the released position, then the area of the pole tip $S_{\mathrm{p}}$ can be taken as $S_{\text {up: }}$ :

$S_{\mathrm{p}}=\pi \cdot d_{\mathrm{p}}^{2} / 4$,

where $d_{\mathrm{p}}$ is the diameter of the pole tip.

The heat flux $P_{\mathrm{c}}$ dissipated into the environment from the entire cooling surface of the magnetic circuit is equal to the sum of $P_{\mathrm{dn}}$ and $P_{\mathrm{up}}$ :

$P_{\mathrm{c}}=\theta_{\mathrm{c}} / R_{\theta \mathrm{dn}}+\theta_{\mathrm{c}} / R_{\theta \mathrm{up}}=\theta_{\mathrm{c}} \cdot\left(R_{\theta \mathrm{dn}}+R_{\theta \mathrm{up}}\right) /\left(R_{\theta \mathrm{dn}} \cdot R_{\theta \mathrm{up}}\right)=$

$=\theta_{\mathrm{c}} / R_{\theta \mathrm{c}}=\theta_{\mathrm{c}} \cdot k_{\mathrm{c}} \cdot S$,

where $R_{\theta \mathrm{c}}$ is the resulting thermal resistance to cooling from the surface of the magnetic core; $S$ is the area of an arbitrary surface; $k_{\mathrm{c}}$ is the equivalent heat transfer coefficient from the surface of the magnetic core reduced to surface $S$ :

$k_{\mathrm{c}}=\left(\left(R_{\theta \mathrm{dn}}+R_{\theta \mathrm{up}}\right) /\left(R_{\theta \mathrm{dn}} \cdot R_{\theta \mathrm{up}}\right)\right) / S=\left(k_{\mathrm{dn}} \cdot S_{\mathrm{dn}}+k_{\text {up }} \cdot S_{\text {up }}\right) / S$.

Heat transfer coefficients.

The heat transfer coefficients $k$ from the solid's surface are usually represented as a sum of the convective $\left(k_{\mathrm{c}}\right)$ and radiant $\left(k_{\mathrm{r}}\right)$ heat transfer coefficients. A technique of the determination of these coefficients used at this problem solution is considered below.

The radiant heat transfer coefficient may be in principle determined from the Stefan-Boltzmann law for each point of the radiating surface if the temperature $\vartheta$ of this point, the temperature $\vartheta_{\mathrm{a}}$ of the region to which the energy is radiated, and the emissivity $\varepsilon$ of the radiating surface are known:

$k_{\mathrm{r}}=\frac{k_{1} \cdot \varepsilon}{\theta}\left[\left(\frac{\theta+\vartheta_{\mathrm{a}}+273}{100}\right)^{4}-\left(\frac{\vartheta_{\mathrm{a}}+273}{100}\right)^{4}\right]$,

where $k_{1}=k_{\mathrm{B}} \cdot 10^{8}=5.67 \mathrm{~W} \cdot \mathrm{m}^{-2} \cdot \mathrm{K}^{-4}$ is the coefficient of radiation of the absolutely black body, $k_{\mathrm{B}}$ is the StefanBoltzmann constant $-k_{\mathrm{B}}=5.67 \cdot 10^{-8} \mathrm{~W} \cdot \mathrm{m}^{-2} \cdot \mathrm{K}^{-4}, \varepsilon$ is the emissivity (in the calculations we took $\varepsilon=0.5$ ) $\theta$ is the temperature rise $\left(\theta=\vartheta-\vartheta_{\mathrm{a}}\right)$.

Convective heat transfer coefficient depends on many factors, but its value adapted to the operating conditions of electrical apparatus can be determined by the formula [2]: $k_{\mathrm{c}}=k \cdot(\theta / l)^{0,25}$,

where $k$ is the empirical coefficient equal to 1.33 for vertical surfaces, with $1.33 \cdot 1.3=1.73$ for a flat surface that radiates heat upward, and $1.33 \cdot 0.7=0.93$ for a flat surface that radiates heat down; $l$ is the determining size, for which the vertical size is taken for vertical surfaces, therefore, for the external surface of the shell $l=l_{\mathrm{w}}$; for horizontal rectangular surfaces, $l$ is taken to be smaller, and for round surfaces the diameter is taken, therefore, to calculate the convective heat transfer coefficient from the yoke surface $l=b_{\mathrm{y}}$, from the armature surface $l=b_{\mathrm{a}}$ (if the electromagnet operated) otherwise $l=d_{\mathrm{p}}$.

Thus, the heat transfer coefficients can be calculated by the formulas:

$k_{\mathrm{e}}=\frac{5,67 \cdot \varepsilon}{\theta_{\mathrm{e}}} \cdot\left[\left(\frac{\theta_{\mathrm{e}}+\vartheta_{\mathrm{a}}+273}{100}\right)^{4}-\left(\frac{\vartheta_{\mathrm{a}}+273}{100}\right)^{4}\right]+1,33 \cdot\left(\theta_{\mathrm{e}} / l_{\mathrm{w}}\right)^{0,25},(15)$

$k_{\mathrm{dn}}=\frac{5,67 \cdot \varepsilon}{\theta_{\mathrm{c}}} \cdot\left[\left(\frac{\theta_{\mathrm{c}}+\vartheta_{\mathrm{a}}+273}{100}\right)^{4}-\left(\frac{\vartheta_{\mathrm{a}}+273}{100}\right)^{4}\right]+1,73 \cdot\left(\theta_{\mathrm{c}} / b_{\mathrm{y}}\right)^{0,25},(16)$

$k_{\text {up }}=\frac{5,67 \cdot \varepsilon}{\theta_{\mathrm{c}}} \cdot\left[\left(\frac{\theta_{\mathrm{c}}+\vartheta_{\mathrm{a}}+273}{100}\right)^{4}-\left(\frac{\vartheta_{\mathrm{a}}+273}{100}\right)^{4}\right]+0,93 \cdot\left(\theta_{\mathrm{c}} / l\right)^{0,25} \cdot(17$

In expression (17), the value of $l$ is taken equal to $b_{\mathrm{a}}$ if the electromagnet operated, otherwise $l=d_{\mathrm{p}}$.

Thermal conductivity.

Methods for calculating the equivalent thermal conductivity $\lambda_{\mathrm{w}}$ of windings were considered in the works of a number of authors in the $30 \mathrm{~s}-60 \mathrm{~s}$ of the last century [10-12]. In those works, empirical formulas are presented that were obtained by processing experimental data for impregnated windings. Among them there is a formula used in our calculations:

$\lambda=\lambda_{\mathrm{i}} \cdot 0,5 \cdot\left[1,45 \cdot(d / \Delta)^{0,75}+(d / \Delta)^{0,67}\right]$,

where $d$ is the diameter of the winding wire, $\Delta$ is the thickness of the insulation of the wire. $\lambda_{\mathrm{i}}$ is the thermal conductivity of internal insulation, depending on the average temperature:

$\lambda_{\mathrm{i}}=\lambda_{\mathrm{i} 0} \cdot\left(1+\alpha_{\lambda 0} \cdot \vartheta_{\mathrm{av}}\right)=\lambda_{\mathrm{ia}} \cdot\left(1+\alpha_{\lambda \mathrm{a}} \cdot \theta_{\mathrm{av}}\right)$,

where $\lambda_{\mathrm{i} 0}, \lambda_{\mathrm{ia}}$ are the thermal conductivities of the internal insulation, respectively, at temperature of $0^{\circ} \mathrm{C}$ and at ambient temperature $\vartheta_{\mathrm{av}} ; \alpha_{\lambda 0}, \alpha_{\lambda_{\mathrm{a}}}$ is the temperature coefficient of thermal conductivity of the internal insulation, assigned respectively to temperature $0^{\circ} \mathrm{C}$ and to ambient temperature:

$\lambda_{\mathrm{ia}}=\lambda_{\mathrm{i} 0} \cdot\left(1+\alpha_{\lambda 0} \cdot \vartheta_{\mathrm{av}}\right) ; \quad \alpha_{\lambda \mathrm{a}}=\alpha_{\lambda 0} /\left(1+\alpha_{\lambda 0} \cdot \vartheta_{\mathrm{av}}\right)$.

In this work, when calculating the equivalent thermal conductivities of the booster and holding windings, the same insulation characteristics were taken: $\lambda_{\mathrm{i} 0}=0.32 \mathrm{~W} /(\mathrm{m} \cdot \mathrm{K})$, $\alpha_{\lambda_{0}}=0.00181 / \mathrm{K}$ (at temperature $\vartheta_{\mathrm{av}}=35^{\circ} \mathrm{C}$ we have $\left.\lambda_{\mathrm{ia}}=0,33, \alpha_{\lambda \mathrm{a}}=0.0017\right)$. However, since wires of different diameters are used in these windings $\left(d_{\mathrm{b}}=0.28 \mathrm{~mm}\right.$, $\left.\Delta_{\mathrm{b}}=0.025 \mathrm{~mm}, d_{\mathrm{h}}=0.18 \mathrm{~mm}, \Delta_{\mathrm{h}}=0.015 \mathrm{~mm}\right)$ and, in addition, they differ from each other by average temperatures, the equivalent heat conductivities of these windings will also differ from each other, for the calculation of which the following formulas are used:

$\lambda_{\mathrm{b}}=2,35 \cdot\left(1+0,0017 \cdot \theta_{\mathrm{bav}}\right)$,

$\lambda_{\mathrm{h}}=1,98 \cdot\left(1+0,0017 \cdot \theta_{\mathrm{hav}}\right)$. 


\section{Differential equations and density of heat sources.}

The system of differential equations, which is used to solve the problem of calculating the stationary temperature field $\vartheta$ in an electromagnet, consists of $n$ (in the number of subdomains) Poisson (for subdomains with internal heat sources) and Laplace (for subdomains without internal sources) differential heat transfer equations. This system looks like this $[2,14,15]$ :

$-\operatorname{div}\left(\lambda_{\mathrm{w} k} \cdot \operatorname{grad} \vartheta\right)=q$

for subdomains with internal heat sources (windings) with number $k$ and thermal conductivity $\lambda_{\mathrm{w} k}$, and

$\operatorname{div}\left(\lambda_{k} \cdot \operatorname{grad} \vartheta\right)=0$

for subdomains without internal heat sources, where $q$ is the volumetric density of internal heat sources; $\lambda_{k}$ is the thermal conductivity of the material of the subdomain with number $k$.

In our problem, four subdomains are considered - the frame and the shell (without internal heat sources) and two windings - the booster and holding (both with internal heat sources). In the iterative process of calculating the stationary thermal field, at each iteration the rms currents $I_{1}, I_{2}$ which pass sequentially through all the turns of the corresponding windings are determined. It should be borne in mind that although the current density in all turns is the same the turns will be heated differently,

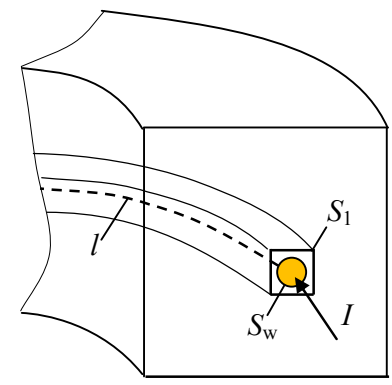

Fig. 3. To the determination of volumetric density of heat sources since the specific resistance of the conductor material depends on temperature (in the temperature range from $0^{\circ} \mathrm{C}$ to $200^{\circ} \mathrm{C}$ this dependence has an almost linear character), in coils with higher temperature more energy will be released than in coils with lower temperature.

In the general case, the density of sources is defined as the derivative in volume of the power loss. This derivative can be replaced by the ratio of small quantities - the power losses in the turn $\Delta P$ and the volume occupied by the turn, taking into account the insulation of the conductor and the internal insulation of the winding $\Delta V$ :

$q=\frac{\mathrm{d} P}{\mathrm{~d} V} \approx \frac{\Delta P}{\Delta V}$.

Since shunt windings contain a large number of turns, the volume occupied by one turn and the power dissipated in one turn can be considered with a high degree of certainty as small quantities:

$$
\begin{aligned}
& \Delta P=I^{2} \cdot \rho_{0} \cdot\left(1+\alpha_{0} \cdot \vartheta\right) \cdot l / S_{\mathrm{w}}, \\
& \Delta V=l \cdot S_{1}=l \cdot S_{\mathrm{w}} / k_{\mathrm{f}},
\end{aligned}
$$

where $I$ is the rms current in the winding (and in the turn); $\rho_{0}$ is the specific resistance of the material of the winding wire at $0^{\circ} \mathrm{C}$ (for copper $\rho_{0}=1.586 \cdot 10^{-8} \Omega \cdot \mathrm{m}$ ); $\alpha_{0}$ is the temperature coefficient of resistivity, referred to the temperature of $0^{\circ} \mathrm{C}$ (for copper $\alpha_{0}=0.004231 / \mathrm{K}$ ); $l$ is the length of the turn; $S_{\mathrm{w}}$ is the cross-sectional area of the winding wire; $S_{1}$ is the cross-sectional area occupied by the cross-section of the turn, taking into account the insulation of the conductor and the internal insulation of the winding; $k_{\mathrm{f}}$ is the fill factor of the winding space with copper.

Substituting (14) and (15) into (13), we obtain:

$q=J^{2} \cdot k_{\mathrm{f}} \cdot \rho_{0} \cdot\left(1+\alpha_{0} \cdot \vartheta\right)=q_{0} \cdot\left(1+\alpha_{0} \cdot \vartheta\right)$,

where $J$ is the rms current density in the conductor:

$J=I / S_{\mathrm{w}}$,

$q_{0}=J^{2} \cdot k_{\mathrm{f}} \cdot \rho_{0}$,

The density of the heat sources can be expressed not through the temperature $\vartheta$, but through the temperature rise $\theta$ over the ambient temperature $\vartheta_{\mathrm{a}}$ :

$q=q_{\mathrm{a}} \cdot\left(1+\alpha_{\mathrm{a}} \cdot \theta\right)$,

where

$q_{\mathrm{a}}=q_{0} \cdot\left(1+\alpha_{0} \cdot \vartheta_{\mathrm{a}}\right)$,

$\alpha_{\mathrm{a}}=\alpha_{0} /\left(1+\alpha_{0} \cdot \vartheta_{\mathrm{a}}\right)$.

The system of equations in 1D formulation of the problem of calculating the temperature field.

As noted above, in this problem, four adjacent subdomains are considered, the axial section of each of which has a rectangular shape: the frame, the booster winding, the holding winding as well as the shell of the coil. The letters in bold are used hereinafter as markers denoting the belonging of a particular physical quantity to the corresponding subdomain. The axial dimensions of the cross-sections of these domains far exceed their radial dimensions, which gives reason to solve this problem in $1 \mathrm{D}$ formulation. The corresponding differential equations describing the distribution of temperature rise in these subdomains in a cylindrical coordinate system take the following form:

$\frac{\mathrm{d}^{2} \theta_{\mathrm{f}}}{\mathrm{d} r^{2}}+\frac{1}{r} \cdot \frac{\mathrm{d} \theta_{\mathrm{f}}}{\mathrm{d} r}=0$

$\frac{\mathrm{d}^{2} \theta_{\mathrm{b}}}{\mathrm{d} r^{2}}+\frac{1}{r} \cdot \frac{\mathrm{d} \theta_{\mathrm{b}}}{\mathrm{d} r}=-\frac{q_{\mathrm{ab}}}{\lambda_{\mathrm{b}}} \cdot\left(1+\alpha_{\mathrm{a}} \cdot \theta_{\mathrm{b}}\right) ;$

$\frac{\mathrm{d}^{2} \theta_{\mathrm{h}}}{\mathrm{d} r^{2}}+\frac{1}{r} \cdot \frac{\mathrm{d} \theta_{\mathrm{h}}}{\mathrm{d} r}=-\frac{q_{\mathrm{ah}}}{\lambda_{\mathrm{h}}} \cdot\left(1+\alpha_{\mathrm{a}} \cdot \theta_{\mathrm{h}}\right) ;$

$\frac{\mathrm{d}^{2} \theta_{\mathrm{s}}}{\mathrm{d} r^{2}}+\frac{1}{r} \cdot \frac{\mathrm{d} \theta_{\mathrm{s}}}{\mathrm{d} r}=0$.

The general solutions of these equations have the following form:

$\theta_{\mathrm{f}}=C_{1}+C_{2} \cdot \ln (r)$;

$\theta_{\mathrm{b}}=C_{3} \cdot \mathrm{J}_{0}\left(\sqrt{\frac{q_{\mathrm{ab}} \cdot \alpha_{\mathrm{a}}}{\lambda_{\mathrm{b}}}} \cdot r\right)+C_{4} \cdot \mathrm{Y}_{0}\left(\sqrt{\frac{q_{\mathrm{ab}} \cdot \alpha_{\mathrm{a}}}{\lambda_{\mathrm{b}}}} \cdot r\right)-\frac{1}{\alpha_{\mathrm{a}}} ;$

$\theta_{\mathrm{h}}=C_{5} \cdot \mathrm{J}_{0}\left(\sqrt{\frac{q_{\mathrm{ah}} \cdot \alpha_{\mathrm{a}}}{\lambda_{\mathrm{h}}}} \cdot r\right)+C_{6} \cdot \mathrm{Y}_{0}\left(\sqrt{\frac{q_{\mathrm{ah}} \cdot \alpha_{\mathrm{a}}}{\lambda_{\mathrm{h}}}} \cdot r\right)-\frac{1}{\alpha_{\mathrm{a}}} ;$

$\theta_{\mathrm{s}}=C_{7}+C_{8} \cdot \ln (r)$,

where $\mathrm{J}_{0}, \mathrm{Y}_{0}$ are the zero-order Bessel functions of the first and second kind.

Calculation of the distribution of temperature rises, based on the conditions of uniqueness of the solution.

Equations (33) - (36) are second-order equations, the general solution of each of them (38) - (40) includes two arbitrary constants - a total of eight constants. To determine 
them under specific heat transfer conditions, it is necessary to compose eight equations that determine the uniqueness of the solution. The joint solution of these equations will make it possible to determine the values of the indicated arbitrary constants and to obtain particular solutions, that is, to find the temperature distribution in the subdomains that correspond to the formulated uniqueness conditions.

Six of the eight conditions mentioned are the conditions of continuity - at the points of conjugation of the subdomains the values of the temperature rises and heat fluxes should be continuous (should not change stepwise):

$$
\begin{aligned}
& \theta_{\mathrm{f}}\left(r_{\mathrm{f}}\right)=\theta_{\mathrm{b}}\left(r_{\mathrm{f}}\right) ; \\
& \theta_{\mathrm{b}}\left(r_{\mathrm{b}}\right)=\theta_{\mathrm{h}}\left(r_{\mathrm{b}}\right) ; \\
& \theta_{\mathrm{h}}\left(r_{\mathrm{h}}\right)=\theta_{\mathrm{s}}\left(r_{\mathrm{h}}\right) ; \\
& {\left[\lambda_{\mathrm{f}} \cdot \frac{\mathrm{d} \theta_{\mathrm{f}}}{\mathrm{d} r}=\lambda_{\mathrm{b}} \cdot \frac{\mathrm{d} \theta_{\mathrm{b}}}{\mathrm{d} r}\right]_{r=r_{\mathrm{f}}} ;} \\
& {\left[\lambda_{\mathrm{b}} \cdot \frac{\mathrm{d} \theta_{\mathrm{b}}}{\mathrm{d} r}=\lambda_{\mathrm{h}} \cdot \frac{\mathrm{d} \theta_{\mathrm{h}}}{\mathrm{d} r}\right]_{r=r_{\mathrm{b}}} ;} \\
& {\left[\lambda_{\mathrm{h}} \cdot \frac{\mathrm{d} \theta_{\mathrm{h}}}{\mathrm{d} r}=\lambda_{\mathrm{s}} \cdot \frac{\mathrm{d} \theta_{\mathrm{s}}}{\mathrm{d} r}\right]_{r=r_{\mathrm{h}}} ;}
\end{aligned}
$$

The remaining two conditions are determined from the boundary conditions - on the external surface of the shell of the coil and on the internal surface of the tubular part of the frame. The boundary condition on the external surface of the shell of the coil is obtained on the basis of the equality of the heat flux approaching the external surface of the shell from its thickness and the heat flux passing into the surrounding air. The first of them is determined based on the Fourier law:

$$
P_{\mathrm{e}}=-\left.\lambda_{\mathrm{s}} \cdot\left(\operatorname{grad}_{\mathrm{n}} \theta_{\mathrm{s}}\right)\right|_{r=r_{\mathrm{e}}} \cdot S_{\mathrm{e}}=-\left.\lambda_{\mathrm{s}} \cdot \frac{\mathrm{d} \theta_{\mathrm{s}}}{\mathrm{d} r}\right|_{r=r_{\mathrm{e}}} \cdot S_{\mathrm{f}}
$$

where $S_{\mathrm{e}}$ is calculated by (1).

Heat flow to ambient air is determined based on Newton formula:

$$
P_{\mathrm{e}}=k_{\mathrm{e}} \cdot \theta_{\mathrm{e}} \cdot S_{\mathrm{e}}=k_{\mathrm{e}} \cdot \theta_{\mathrm{s}}\left(r_{\mathrm{e}}\right) \cdot S_{\mathrm{e}}
$$

Equating the right sides of (47) and (48), we obtain the boundary condition on the external surface of the coil shell:

$\left[-\lambda_{\mathrm{s}} \cdot \frac{\mathrm{d} \theta_{\mathrm{s}}}{\mathrm{d} r}=k_{\mathrm{e}} \cdot \theta_{\mathrm{s}}\right]_{r=r_{\mathrm{e}}}$.

The boundary condition on the internal surface of the tubular part of the frame is determined based on the balance of heat fluxes on this surface (Fig. 2):

$P_{\mathrm{m}}+P_{\mathrm{f}}=P_{\mathrm{c}}$.

Heat flux approaching the internal surface of the frame from its thickness is determined based on the Fourier law:

$$
P_{\mathrm{f}}=-\left.\lambda_{\mathrm{f}} \cdot\left(\operatorname{grad}_{\mathrm{n}} \theta_{\mathrm{f}}\right)\right|_{r=r_{\mathrm{s}}} \cdot S_{\mathrm{f}}=\left.\lambda_{\mathrm{f}} \cdot \frac{\mathrm{d} \theta_{\mathrm{f}}}{\mathrm{d} r}\right|_{r=r_{\mathrm{e}}} \cdot S_{\mathrm{f}},
$$

where $S_{\mathrm{f}}$ is the area of the internal surface of the tubular part of the frame:

$S_{\mathrm{f}}=2 \cdot \pi \cdot r_{\mathrm{c}} \cdot l_{\mathrm{w}}$,

In expression (51), in contrast to (47), the "-" sign is missing after the second equal sign, since the direction of the external normal to the surface $S_{\mathrm{f}}$ is opposite to the direction of the $r$ axis.
The heat flux $P_{\mathrm{c}}$ dissipated into the environment from the entire cooling surface of the magnetic circuit can be calculated based on (11), in which the surface $S_{\mathrm{f}}$ is taken as an arbitrary surface $S$ :

$P_{\mathrm{c}}=\theta_{\mathrm{c}} \cdot k_{\mathrm{c}} \cdot S_{\mathrm{f}}=\theta_{\mathrm{f}}\left(r_{\mathrm{c}}\right) \cdot k_{\mathrm{c}} \cdot S_{\mathrm{f}}$

In this case, the equivalent heat transfer coefficient from the surface of the magnetic core reduced to the surface $S_{\mathrm{f}}$ is equal to:

$k_{\mathrm{c}}=\left(k_{\mathrm{dn}} \cdot S_{\mathrm{dn}}+k_{\text {up }} \cdot S_{\text {up }}\right) / S_{\mathrm{f}}$.

Substituting (53) and (51) into (50), we obtain the boundary condition on the internal surface of the tubular part of the frame:

$$
\left[\lambda_{\mathrm{f}} \cdot \frac{\mathrm{d} \theta_{\mathrm{f}}}{\mathrm{d} r}=k_{\mathrm{c}} \cdot \theta_{\mathrm{f}}-P_{\mathrm{m}} / S_{\mathrm{f}}\right]_{r=r_{\mathrm{c}}} .
$$

\section{RMS currents in the windings. Power losses in the magnetic core.}

The procedure for calculating the currents in the windings and the losses in the magnetic core is determined by the connection circuit of the windings to the power source and its type (DC voltage source or AC voltage source with a rectifier). In this paper, as an example, we consider the control device that is most often used in contactors (Fig. 4). The calculation circuit differs from the circuit diagram by the presence of scattering inductances $L_{\sigma \mathrm{B}}$ and $L_{\sigma \mathrm{H}}$ due to fluxes not passing through the sections of the magnetic core.

In previous works $[16,17]$, the features of the operation of this device were analyzed in detail, and a methodology for calculating the dynamic characteristics of an electromagnet, including the currents in its booster and holding windings, was considered. This technique is based on the joint solution of the equations of the electric circuit (Fig. 4b) and the magnetic circuit (Fig. 5b).

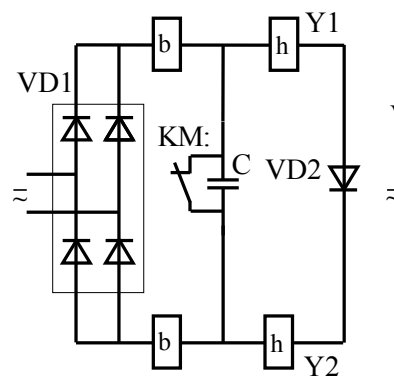

a

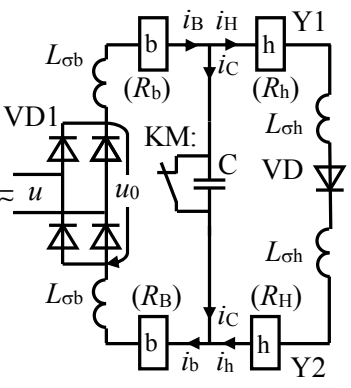

b
Fig. 4. Circuit diagram (a) and calculation circuit (b) of the forced control system, which is used in low and medium voltage vacuum contactors and in some SF6 medium voltage contactors [16]; $u$ is the instantaneous value of the nominative voltage of the control circuit; $u_{0}$ is the voltage at the output of the diode bridge

This electrical circuit is too complicated for programming. Its description will be much simpler if the parallel connection of the capacitor $C$ with the auxiliary control contact KM:, which is closed when the coordinate $s$ of the armature stroke does not exceed the value of the opening stroke of this contact $s_{\mathrm{a}}$, is replaced by one capacitor, whose capacitance is assumed to be very large $-C_{\mathrm{M}}$ for $s \leq s_{\mathrm{a}}$, and for $s>s_{\mathrm{a}}$ the capacitance of this capacitor becomes equal to its nominal value $C_{0}$ :

$C=\left\{\begin{array}{lll}C_{\mathrm{M}} & \text { at } & s \leq s_{\mathrm{a}} \\ C_{0} & \text { at } & s>s_{\mathrm{a}}\end{array}\right.$. 
In this case, we obtain the following differential equations:

$$
\begin{aligned}
& u_{0}=2 \cdot R_{\mathrm{b}} \cdot i_{\mathrm{b}}+2 \cdot L_{\sigma \mathrm{b}} \cdot \frac{\mathrm{d} i_{\mathrm{b}}}{\mathrm{d} t}+2 \cdot N_{\mathrm{b}} \cdot \frac{\mathrm{d} \Phi_{0}}{\mathrm{~d} t}+u_{\mathrm{C}} \\
& u_{\mathrm{C}}=2 \cdot R_{\mathrm{h}} \cdot i_{\mathrm{h}}+2 \cdot L_{\sigma \mathrm{h}} \cdot \frac{\mathrm{d} i_{\mathrm{h}}}{\mathrm{d} t}+2 \cdot N_{\mathrm{h}} \cdot \frac{\mathrm{d} \Phi_{0}}{\mathrm{~d} t}+u_{\mathrm{d}}\left(i_{\mathrm{h}}\right) ; \\
& C \cdot \frac{\mathrm{d} u_{\mathrm{C}}}{\mathrm{d} t}=i_{\mathrm{b}}-i_{\mathrm{h}},
\end{aligned}
$$

where $N_{\mathrm{b}}, N_{\mathrm{h}}$ are the number of turns of the booster (b) and holding (h) windings, respectively.

In [16] various variants of magnetic circuit equivalent circuits were considered, including a relatively simple two-contour circuit with a concentrated scattering flux (Fig. 5b).

The equations compiled for two contours with magnetic fluxes $\Phi_{0}$ and $\Phi_{1}$ have the following form:

$$
\begin{aligned}
& -G_{\mathrm{a}} \cdot \frac{\mathrm{d} \Phi_{0}}{\mathrm{~d} t}=H\left(\Phi_{0} / S_{\mathrm{a}}\right) \cdot l_{\mathrm{a}}+\frac{2 \cdot \Phi_{0}}{\Lambda_{\delta}}-\left(\Phi_{1}-\Phi_{0}\right) / \Lambda_{\mathrm{ofe}} ; \\
& 2 \cdot i_{\mathrm{b}} \cdot N_{\mathrm{b}}+2 \cdot i_{\mathrm{h}} \cdot N_{\mathrm{H}}-\left(2 \cdot G_{\mathrm{c}}+G_{\mathrm{y}}\right) \cdot \frac{\mathrm{d} \Phi_{1}}{\mathrm{~d} t}= \\
& =H\left(\Phi_{1} / S_{\mathrm{y}}\right) \cdot l_{\mathrm{y}}+2 \cdot H\left(\Phi_{1} / S_{\mathrm{c}}\right) \cdot l_{\mathrm{c}}+\left(\Phi_{1}-\Phi_{0}\right) / \Lambda_{\mathrm{ofe}}
\end{aligned} .
$$

The designations of the quantities in (57)-(61) correspond to the designations given in Fig. $4 b$, 5. Here, the MMF $F_{\mathrm{m}}$ is the sum of the MMFs of the booster and the holding windings:

$$
F_{\mathrm{m}}=i_{\mathrm{b}} \cdot N_{\mathrm{b}}+i_{\mathrm{h}} \cdot N_{\mathrm{h}} \text {. }
$$

In addition, in (60), (61) it is indicated: $G_{\mathrm{c}}, G_{\mathrm{a}}, G_{\mathrm{y}}$ are the electrical conductivities in the path of eddy currents in the core, armature, and yoke. The values of these quantities can be determined by the following formulas [1]:

$G_{\mathrm{c}}=l_{\mathrm{c}} /\left(8 \cdot \pi \cdot \rho_{\mathrm{st}}\right)$;

$G_{\mathrm{a}, \mathrm{y}}=l_{\mathrm{a}, \mathrm{y}} /\left(16 \cdot \rho_{\mathrm{st}} \cdot\left(h_{\mathrm{a}, \mathrm{y}} / b_{\mathrm{a}, \mathrm{y}}+b_{\mathrm{a}, \mathrm{y})} / h_{\mathrm{a}, \mathrm{y}}\right)\right)$,

where $l_{\mathrm{c}}$ is the length of the core; $\rho_{\mathrm{st}}$ is the specific resistance of the material of the magnetic core (steel); $h_{\mathrm{a}}$ is the height of the armature part; $h_{\mathrm{y}}$ is the height of the yoke part.

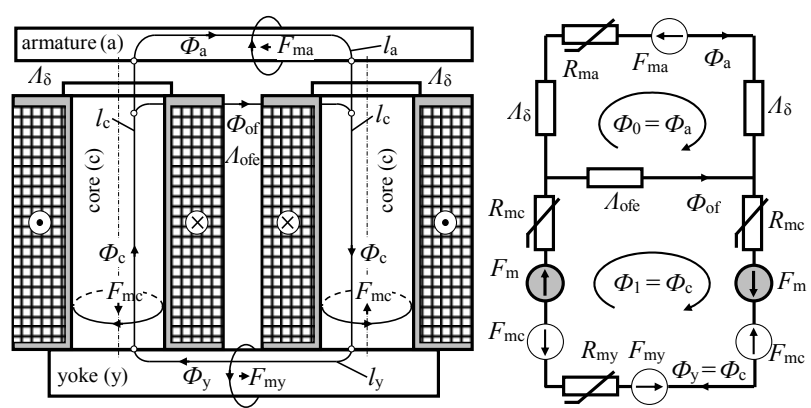

Fig. 5. Sketch of the double-rod electromagnet magnetic circuit and its simplified equivalent circuit used in calculations of transients

If this device is powered from a source with DC voltage value $U$, then the calculation of currents in the windings in stationary mode does not cause difficulties. For the circuit shown in Fig. $4 a$, the corresponding formulas look like this. If the electromagnet operated, then all the windings turn on in series and there are also three diodes in this circuit - two diodes of the rectifier bridge VD1 and a «locking» diode VD2, therefore:

$I_{\mathrm{b}}=I_{\mathrm{h}}=\left(U-3 \cdot U_{\mathrm{d}}\right) /\left(2 \cdot\left(R_{\mathrm{b}}+R_{\mathrm{h}}\right)\right)$.
If the electromagnet did not operate and the contact $\mathrm{KM}$ : did not open, then the holding windings remain shorted by the contact KM: and the current does not flow in them. The booster windings remain connected in series and there are two diodes of the rectifier bridge VD1 in their circuit, therefore:

$I_{\mathrm{b}}=\left(U-2 \cdot U_{\mathrm{d}}\right) /\left(2 \cdot R_{\mathrm{b}}\right) ; I_{\mathrm{h}}=0$.

The voltage drop on the diode is small - about $1 \mathrm{~V}$, but when powered by an ultra-low voltage source, three diodes give a significant decrease in current in the windings.

Since there are no current pulsations in the windings when powered from a DC voltage source in the stationary mode, there are no pulsations of the magnetic flux in the magnetic core, and therefore losses in it:

$P_{\mathrm{m}}=0$.

If this device is powered by an $\mathrm{AC}$ voltage source, for example, with frequency of $50 \mathrm{~Hz}$, then a two-half-period rectified voltage is formed at the output of the diode bridge - a periodic curve with frequency of the fundamental harmonic of the variable component equal to $100 \mathrm{~Hz}$. The presence of nonlinear elements in the electric and magnetic circuits leads to the appearance of higher harmonics, which greatly complicates the calculation of such circuits.

In [16] an algorithm focused on the use of the Maple computing environment was considered, developed to calculate the dynamics of electromagnets operating in complex forced control systems, for example, in the forced control device circuit shown in Fig. $4 a$. Comparison of the calculation results by this algorithm with experimental data [16] showed that even a simplified representation of the magnetic circuit in the form of a two-contour equivalent circuit provides good agreement between the results of mathematical and field experiments. This holds, even when the control device is powered from an AC voltage source, when complex shapes of current curves in windings are observed.

Calculations and experiments also show that the stable shape of currents curves in the booster and holding windings occurs almost immediately after the completion of the movement of the armature. For an electromagnet, the dimensions of which are given in [16], the response time ranges from $50 \mathrm{~ms}$ (with supply voltage equal to the rated voltage of the control circuit $220 \mathrm{~V}$ ) to $80 \mathrm{~ms}$ (with a supply voltage equal to $180 \mathrm{~V})$. At low voltage $(150 \mathrm{~V}$ or less), the electromagnet did not operate, but the shape of the current curves stabilized no later than after $100 \mathrm{~ms}$. Figure 6 shows the curves of changes in currents in the windings during two periods - from $150 \mathrm{~ms}$ to $170 \mathrm{~ms}$ after the beginning of the transient.
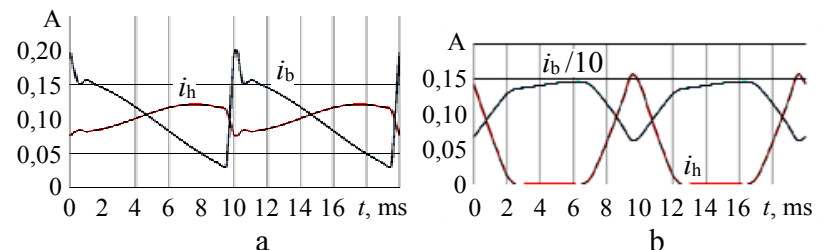

Fig. 6. Curves of current changes in the forced electromagnet windings: a - at supply voltage in the control circuit of $220 \mathrm{~V}$ (the electromagnet operated); $\mathrm{b}$ - at supply voltage of $150 \mathrm{~V}$ (the electromagnet did not operate) 
Apparently, in both modes (the electromagnet operated / did not operate), the transient almost ends quickly enough in $150 \mathrm{~ms}$, that is, after seven to eight periods $T$ of voltage change in the grid of $50 \mathrm{~Hz}$ ). Consequently, there is no need to build a special iterative technique for calculation of currents in stationary mode. It is enough to use a welltested methodology for calculating dynamics, setting a knowingly large finite value of time $t_{\mathrm{k}}$, to record in the computer memory the instantaneous values $i_{\mathrm{b}}$ and $i_{\mathrm{h}}$ of currents in the windings during the last period $T$ and using one of the known numerical integration methods calculate the rms currents $I_{\mathrm{b}}$ and $I_{\mathrm{h}}$ :

$$
I_{\mathrm{b}, \mathrm{h}}=\left[\frac{1}{T} \cdot \int_{t_{\mathrm{k}}-T}^{t_{\mathrm{k}}}\left[i_{\mathrm{b}, \mathrm{h}}(t)\right]^{2} \cdot \mathrm{d} t\right]^{0,5} .
$$

As a result of the joint solution of the equations of the electric and magnetic circuits, it is possible to calculate the magnetic fluxes in the armature, core and yoke, as well as their time derivatives. These derivatives can be considered as EMF in single-turn contours equivalent in losses in the armature, core and yoke and calculate the instantaneous values of currents $i_{\mathrm{a}}, i_{\mathrm{c}}$ and $i_{\mathrm{y}}$ in these circuits in transient mode. Having fixed these instantaneous values during the last period of the calculation of the transient in the computer memory, using one of the known numerical integration methods using a formula similar to (68), it is possible to calculate the rms currents $I_{\mathrm{a}}, I_{\mathrm{c}}, I_{\mathrm{y}}$ and losses in the magnetic core: $P_{\mathrm{m}}=I_{\mathrm{a}}^{2} / G_{\mathrm{a}}+I_{\mathrm{c}}^{2} / G_{\mathrm{c}}+I_{\mathrm{y}}^{2} / G_{\mathrm{y}}$.

An iterative algorithm for calculating the temperature distribution in the windings of forced electromagnets using the Maple computing environment.

In order to calculate the rms currents in the windings, it is necessary to know their resistances, which depend on the average temperature values of the corresponding windings. In order to calculate the temperatures of the windings, it is necessary to know the rms currents in the windings. This problem can be solved using the iteration method:

$0)$ to set arbitrary average values of the temperature rises of the windings $\theta_{\mathrm{bav} i}=\theta_{\mathrm{bav} 0}$ and $\theta_{\mathrm{hav} i}=\theta_{\mathrm{hav} 0}$;

1) to calculate the winding resistances:

$$
R_{\mathrm{b} i}=R_{\mathrm{ba}} \cdot\left(1+\alpha_{\mathrm{a}} \cdot \theta_{\mathrm{bav} i}\right) \text { and } R_{\mathrm{h} i}=R_{\mathrm{ha}} \cdot\left(1+\alpha_{\mathrm{a}} \cdot \theta_{\mathrm{hav} i}\right) \text {; }
$$

2) to calculate the rms currents in the windings and the power losses in the magnetic core according to the technique described in the corresponding section of this paper;

3 ) to calculate the distribution of temperature rises in the booster and holding windings $\theta_{\mathrm{b}}(r)$ and $\theta_{\mathrm{h}}(r)$ according to the procedure described in the corresponding section of this paper;

4) to calculate the volumetric average temperature rises in the booster and holding windings:

$$
\begin{aligned}
& \theta_{\mathrm{bav}}=\left[\frac{2}{r_{\mathrm{b}}^{2}-r_{\mathrm{f}}^{2}} \cdot \int_{r_{\mathrm{f}}}^{r_{\mathrm{b}}} \theta_{\mathrm{b}}(r) \cdot r \cdot \mathrm{d} r\right], \\
& \theta_{\mathrm{hav}}=\left[\frac{2}{r_{\mathrm{h}}^{2}-r_{\mathrm{b}}^{2}} \cdot \int_{r_{\mathrm{b}}}^{\mathrm{r}_{\mathrm{h}}} \theta_{\mathrm{h}}(r) \cdot r \cdot \mathrm{d} r\right] .
\end{aligned}
$$

4) if the obtained values of temperature rises significantly differ from the values of $\theta_{\mathrm{bav} i}$ and $\theta_{\text {havi }}$, that is, the following conditions are not satisfied:

$\left|\left(\theta_{\text {bav } i}-\theta_{\text {bav }}\right) / \theta_{\text {bavi }}\right|<\varepsilon$ and $\left|\left(\theta_{\text {hav } i}-\theta_{\text {hav }}\right) / \theta_{\text {hav } i}\right|<\varepsilon$,

where $\varepsilon$ is a small predetermined positive number, then $\theta_{\text {bavi }}$ and $\theta_{\text {hav } i}$ are assigned the values of $\theta_{\text {bav }}$ and $\theta_{\text {hav }}$, respectively, and the calculations are repeated starting from step 1) for new values of $\theta_{\mathrm{bav} i}$ and $\theta_{\text {havi }}$.

The described calculation cycle is repeated until condition (73) is satisfied.

The experience of calculations shows that this iteration process converges quite quickly (the number of iterations $n$ usually does not exceed 12), and the use of the Maple computing environment significantly simplifies the programming of this very cumbersome task.

\section{Calculation results and comparison with}

\section{experimental data.}

In order to verify the operability of the above technique and algorithm for calculating, the thermal field of electromagnets operating in complex forced control systems, the authors performed test calculations of heating of the electromagnet windings of the serial vacuum contactor KBTH-250/1,14 [16], in which the forced control system the circuit of which is shown in Fig. 4 is used, intended for operation in control networks with a nominal voltage of $220 \mathrm{~V}$. The calculations are performed in accordance with the initial data indicated in [16], with the additions given below (if the corresponding data are not given in the text of this paper): $r_{\mathrm{c}}=13 \mathrm{~mm}$; $r_{\mathrm{f}}=15 \mathrm{~mm} ; r_{\mathrm{b}}=19 \mathrm{~mm} ; r_{\mathrm{h}}=27.5 \mathrm{~mm} ; r_{\mathrm{e}}=29.5 \mathrm{~mm}$; $l_{\text {ap }}=75 \mathrm{~mm} ; \quad l_{\text {yp }}=75 \mathrm{~mm} ; \quad l_{\mathrm{w}}=64 \mathrm{~mm} ; \quad b_{\mathrm{a}}=50 \mathrm{~mm}$; $b_{\mathrm{y}}=70 \mathrm{~mm}$. The designations of the initial data correspond to the designations that are used in the text of this paper. The calculation results are presented in Table 1, which also shows the experimental data indicated to the right of the slashes. As it can be seen, the calculation results are slightly different from the experimental data: the difference does not exceed $10 \%$, which can be considered acceptable for thermal calculations.

Table 1

Results of calculations and experimental data

\begin{tabular}{|l|c|c|c|c|}
\hline$U, \mathrm{~V}$ & $220 \mathrm{DC}$ & $220 \mathrm{AC}$ & $80 \mathrm{DC}$ & $80 \mathrm{AC}$ \\
\hline$\theta_{\mathrm{b}}, \mathrm{K}$ & $62,8 / 61,7$ & $55,5 / 57,9$ & $121,9 / 126$ & $114,1 / 122,5$ \\
\hline$\theta_{\mathrm{h}}, \mathrm{K}$ & $63,9 / 66,9$ & $56,4 / 59,6$ & $117,8 / 112,7$ & $110,6 / 105,9$ \\
\hline$\theta_{\mathrm{c}}, \mathrm{K}$ & $54,6 / 57,3$ & $48,6 / 47,0$ & $111,5 / 112,3$ & $104,6 / 103,4$ \\
\hline$\theta_{\max }, \mathrm{K}$ & $64,2(\mathrm{~h})$ & $56,6(\mathrm{~h})$ & $122(\mathrm{~b})$ & $114,0(\mathrm{~b})$ \\
\hline$R_{\mathrm{b}}, \Omega$ & $79 / 82$ & $77 / 81$ & $91 / 99$ & $90 / 98$ \\
\hline$R_{\mathrm{h}}, \Omega$ & $1115 / 1047$ & $1090 / 1023$ & $1295 / 1193$ & $1271 / 1171$ \\
\hline$I_{\mathrm{b}}, \mathrm{A}$ & $0,092 / 0,093$ & $0,097 / 0,098$ & $0,49 / 0,50$ & $0,463 / 0,475$ \\
\hline$I_{\mathrm{h}}, \mathrm{A}$ & $0,092 / 0,093$ & $0,086 / 0,088$ & $0 / 0$ & $0,025 / 0,025$ \\
\hline$P_{\mathrm{c}}, \mathrm{W}$ & 0 & 0,10 & 0 & 0,15 \\
\hline$I_{\mathrm{c}}, \mathrm{A}$ & 0 & 24,2 & 0 & 16,3 \\
\hline$n$ & 6 & 8 & 12 & 12 \\
\hline
\end{tabular}

Notes:

1. At $U=220 \mathrm{~V}$ (AC and DC), the electromagnet clearly operated, and at $U=80 \mathrm{~V}$ (AC and DC) the electromagnet did not operate.

2. The experimental determination of temperature rise was carried out using the resistance method (IEC 60947-1, 8.3.3.3.2)

Calculations show that despite significant current ripples in the booster winding (Fig. 7), the eddy currents in the magnetic core do not reach such values at which the magnetic core would be a heat source: as can be seen from Table 1, the power of losses in it is at the level of $1-2 \mathrm{~W}$. 
This means that the magnetic core of the electromagnet in such forced control systems can be considered as a kind of radiator contributing to a decrease in the heating of the windings or, while maintaining the temperature of their heating, to a decrease in the consumption of the winding wire. Such an effect can be achieved with certain structural

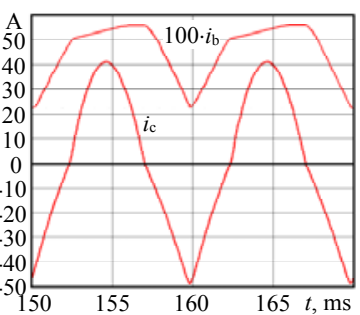

Fig. 7. Currents in the booster winding $i_{\mathrm{b}}$ and in the magnetic core $i_{\mathrm{c}}$ at $U=80 \mathrm{~V} \mathrm{AC}$ and technological solutions: the coil frame should be made of insulating material with large thermal conductivity, and its tubular part should be as small as possible in thickness and it should be tightly pressed on to the core.

\section{Conclusions.}

1. The multiphysics model of stationary heating of the windings presented in the paper allows to take into account the peculiarities of the operation of electromagnets in complex forced control systems, in particular, ripple currents in the windings and losses in the magnetic core when powered by a rectified voltage source.

2. The algorithm developed by the authors for calculating the thermal field of electromagnets operating in forced control systems is a complex iterative cycle. Its implementation is significantly simplified by using the Maple computing environment, which allows to speed up the modeling process, perform cumbersome transformations, and obtain computer simulation results in a convenient tabular and/or graphical form.

3. The adequacy of the developed mathematical model and algorithm for complex shapes of current curves in windings is confirmed by experimental data.

4. The magnetic core of an electromagnet in such forced control systems, not only when powered from DC voltage sources, but when powered from AC voltage sources through a rectifier, can be considered as a kind of radiator that reduces the heating temperature of the windings or, while maintaining their heating temperature, allowing to reduce the consumption of winding wire.

\section{REFERENCES}

1. Klymenko B.V. Forced electromagnetic systems. Moscow, Enegroatomizdat Publ., 1989. 160 p. (Rus).

2. Zalessky A.M., Kukekov G.A. Thermal calculations of electrical apparatus. Leningrad, Energy Publ., 1967. 378 p. (Rus).

3. Loginov V.S. Approximate methods for thermal calculation of the active elements of electrophysical installations. Moscow, Physmatlit Publ., 2009. 272 p. (Rus).

4. Chunihin A.A. Electrical apparatus. General course. Moscow, Energoatomizdat Publ., 1988. 720 p. (Rus).

5. Akimov E.G., Belkin G.S., Godzhello A.G. Fundamentals of the theory of electrical apparatus. Textbook. Ed. P.A. Kurbatov. 5th Edition. St. Petersburg, Lan Publ., 2015. 588 p. (Rus).

6. Kuznetsov R.S. Apparatus for the distribution of electrical energy for voltages up to $1000 \mathrm{~V}$. Moscow, Energy Publ., 1970. 544 p. (Rus). 7. Taev I.S. Electrical control apparatus. Moscow, High school Publ., 1969. 444 p. (Rus).

8. Alexandrov G.N., Borisov V.V., Kaplan G.S. Theory of electrical apparatus: Textbook for Universities. Ed. Prof. G.N. Alexandrov. 2nd Edition. St. Petersburg, Publishing House of SPbTU, 2000. 540 p. (Rus).

9. Pekker I.I., Nikitenko A.G. Calculation of electromagnetic mechanisms on computers. Moscow, Energy Publ., 1967. 168 p. (Rus). 10. Petrov G.N. On the heating of current-flowing coils. Bulletin of Electrical Engineering Industry, 1930, no.2 (Rus).

11. Jakob M. Influence of non-uniform development of heat upon the temperature distribution in electrical coils and similar heat sources of simple form. Trans. ASME, 1943, vol.65, pp. 593-605.

12. Liubchik M.A. Calculation and design of $D C$ and $A C$ electromagnets of direct and alternating current. Moscow, GEI Publ., 1959. 227 p. (Rus).

13. Mikheev M.A., Mikheeva I.M. Heat transfer basics. 2nd Edition. Moscow, Energy Publ., 1977. 344 p. (Rus).

14. Holman J.P. Heat Transfer. McGraw-Hill, NY, 2002. 665 p.

15. Lykov A.V. Heat conductivity theory. Moscow, High school Publ., 1967. 600 p. (Rus).

16. Baida Ye.I., Clemens M., Klymenko B.V., Korol O.G., Pustovoitov P.Ye., Application of the computing environment maple to the calculation of the dynamics of the electromagnets in the complicated systems of forced control. Electrical Engineering \& Electromechanics, 2019, no.3, pp. 18-23. doi: 10.20998/2074-272X.2019.3.03.

17. Korol O.G., Klymenko B.V., Eresko O.V. Investigations of transients in the forced control device of the vacuum contactor monostable electromagnet. Bulletin of NTU «KhPI». Series: Problems of Electrical Machines and Apparatus Perfection. The Theory and Practice, 2018, no.32(1308), pp. 34-40 (Ukr). doi: 10.20998/2079-3944.2018.32.06.

Received 18.07.2019

Ye.I. Baida ${ }^{1}$, M. Clemens $^{2}$, B.V. Klymenko ${ }^{1}$, O.G. Korol ${ }^{1}$, M.G. Pantelyat ${ }^{1}$ P.Ye. Pustovoitov ${ }^{1}$

${ }^{1}$ National Technical University «Kharkiv Polytechnic Institute», 2, Kyrpychova Str., Kharkiv, 61002, Ukraine,

phone+380 57 7076281, e-mail: b.v.klymenko@gmail.com

${ }^{2}$ University of Wuppertal,

Rainer-Gruenter-Straße 21, 42119 Wuppertal, Germany,

phone +49 202 439-1924, e-mail: clemens@uni-wuppertal.de

Peculiarities of calculating stationary heating of windings operating in complex forced control systems.

General description of the research topic. A technique and an algorithm for calculating the thermal field of electromagnets operating in complex forced systems proposed by authors are considered. The widespread use of such devices in electromechanical switching devices allows not only to increase their speed but also significantly reduce the size, mass and energy losses, which indicates the relevance of this topic. The mathematical model of heating the windings of forced electromagnets proposed by the authors is a system of $1 D$ differential equations of stationary heat transfer in a cylindrical coordinate system, supplemented by equations of electrical and magnetic circuits. This model allows to take into account the ripple of the currents in the windings and the losses in the magnetic core due to these ripples, contains certain signs of scientific novelty and represents the goal of the paper. The algorithm developed by the authors for calculating the thermal field of electromagnets operating in forced control systems is a complex iterative cycle. Its implementation is greatly simplified by using the Maple computing environment which allows to realize complicated and cumbersome mathematical transformations, automates the process of computations, and obtain results of numerical simulation in a convenient tabular and/or graphic form, which indicates the practical significance of this works. The results of comparison of computation results with experimental data presented in the paper indicate the adequacy of the model and algorithm proposed. References 17, tables 1, figures 7.

Key words: electromagnets, thermal field, forced control, switching devices, Maple computing environment, computer simulation.

\section{How to cite this article:}

Baida Ye.I., Clemens M., Klymenko B.V., Korol O.G., Pantelyat M.G., Pustovoitov P.Ye. Peculiarities of calculating stationary heating of windings operating in complex forced control systems. Electrical engineering \& electromechanics, 2019, no.5, pp. 12-19. doi: 10.20998/2074-272X.2019.5.02. 